\title{
Does serum angiotensin converting enzyme reflect intensity of alveolitis in sarcoidosis?
}

\author{
RD COHEN, PS BUNTING, HO MEINDOK, DW CHAMBERLAIN, AS REBUCK \\ From the Division of Respiratory Medicine, Toronto Western Hospital, and the Departments of Clinical \\ Biochemistry, Sunnybrook Medical Centre and University of Toronto, Toronto, Canada
}

ABSTRACT Serum angiotensin converting enzyme activity is increased in many patients with pulmonary sarcoidosis and has been proposed as a measure of disease activity. Assay of serum angiotensin converting enzyme, bronchoalveolar lavage, and gallium scans were performed in 27 patients with biopsy proved pulmonary sarcoidosis. There was a positive correlation between serum angiotensin converting enzyme activity and an index of pulmonary gallium uptake assessed by the National Institutes of Health method $(r=0.7, p<0.001)$. There was no significant relationship $(r=0.19)$ between serum angiotensin converting enzyme activity and bronchoalveolar lavage lymphocytes expressed as a proportion of cells recovered. Increase in the enzyme activity had a sensitivity of $50 \%$ as a means of detecting high intensity alveolitis but specificity was only $45 \%$. There was no significant difference in mean angiotensin converting enzyme activity between the following groups: (1) those with positive and those with negative gallium scans; (2) those with bronchoalveolar lavage lymphocyte counts less than or equal to $28 \%$ and those with counts greater than $28 \%$. Although there was a significant correlation between the enzyme activity and one component of the alveolitis of sarcoidosis, the data suggest that serum angiotensin converting enzyme activity alone is neither sensitive nor specific enough for high intensity alveolitis.

Since the observation by Lieberman in 1975 that serum angiotensin converting enzyme activity was increased in patients with pulmonary sarcoidosis,' many investigations have confirmed these findings ${ }^{2-4}$ but differed in their conclusions with respect to the utility of measurements of the enzyme in predicting disease activity. This conflict may be due in part to a lack of uniformity in the selection of the ancillary tests used to identify and quantify the active alveolitic component that precedes permanent structural derangement. ${ }^{10}$

Studies on the natural history of pulmonary sarcoidosis have shown that most patients improve spontaneously with minimal or no impairment of lung function, 20-25\% experience appreciable deterioration in pulmonary function, and $5-10 \%$ eventually die from the disease..$^{11-13}$ Conventional criteria used in the assessment of disease activity,

Address for reprint requests: Professor AS Rebuck, Division of Respiratory Medicine, Toronto Western Hospital, 399 Bathurst Street, Toronto, Ontario, Canada M5T 2SB.

Accepted 11 February 1985 such as clinical features, chest radiographic appearances and results of pulmonary function tests, are insensitive markers of the alveolitis that characterises active disease and abnormalities usually reflect irreversible changes in lung structure and function due to progressive interstitial fibrosis and derangement of alveolar-capillary units. ${ }^{14}$ is The cellular derangements in sarcoidosis have been studied intensively; current understanding emphasises the dual cellular nature of the process, both activated $\mathrm{T}$ lymphocytes and alveolar macrophages being crucial to the initiation and perpetuation of alveolitis. ${ }^{16} 17$ Recently Crystal et al have shown that only patients with "high intensity" alveolitis, as defined by a lavage $T$ cell count greater than or equal to $28 \%$ of cells recovered and a positive gallium scan, were at risk for subsequent deterioration in pulmonary function. ${ }^{10}$

Given the limitations of physiological measurement as a means of assessing the alveolitis, emphasis has been placed on analysis of lymphocytes harvested at bronchoalveolar lavage and uptake of gallium 67 by alveolar macrophages in assessing each component of the inflammatory response. ${ }^{10}$ The 
present study was undertaken to examine the relationship of serum angiotensin converting enzyme activity to each of these components and to determine its sensitivity and specificity as an indicator of abnormal results.

\section{Methods}

The study population consisted of 27 patients with biopsy proved pulmonary sarcoidosis with a mean age of 49.7 (SD 14.2) years. There were 15 women and 12 men. Twenty three $(85 \%)$ were untreated at the time of entry into the study, or had not taken prednisone for a minimum of three months before being studied; four patients were taking prednisone. One patient was at radiographic stage 0 (normal chest film), three were at stage I (hilar adenopathy only), 11 were at stage II (hilar adenopathy and pulmonary infiltrates), and 12 were at stage III (pulmonary infiltrates only).

\section{ANGIOTENSIN CONVERTING ENZYME}

Serum angiotensin converting enzyme was measured by the method of Friedland and Silverstein. ${ }^{18}$ The substrate used was hippuryl-histidyl-leucine, which is hydrolysed by the enzyme to hippuric acid and histidyl-leucine. The latter is reacted with an orthophthaldialdehyde to produce a fluorescent product. Enzyme activity was measured as a function of the fluorescence with excitation at $360 \mathrm{~nm}$ and emission at $500 \mathrm{~nm}$. Blood was taken from patients within seven days of the gallium scan and the serum separated immediately and stored frozen until assayed within 14 days. Our reference range for the assay is $12-52$ units/litre, which is similar to that described by Friedland and Silverstein. ${ }^{18}$

\section{BRONCHOALVEOLAR LAVAGE}

Bronchoalveolar lavage was performed according to previously published methods. ${ }^{14}$ In brief, after topical anaesthesia with $4 \%$ lignocaine and intravenous diazepam, lavage was performed in either the right middle lobe or the lingula with five $20 \mathrm{ml}$ aliquots of normal saline. Suction of $60-100 \mathrm{~cm} \mathrm{H}_{2} \mathrm{O}$ was applied and the lavage fluid collected in a sterile trap. Bronchoalveolar lavage fluid was filtered through $5 \mu \mathrm{m}$ cytology filters (Millipore or Gelman) with a negative pressure of $25 \mathrm{~mm} \mathrm{Hg}$. The filters were immediately fixed in $95 \%$ ethanol and the slides stained according to the Papanicolau method, as previously described. ${ }^{14}$ A differential cell count was carried out on 300-500 non-epithelial cells.

GALLIUM 67 SCANNING

Gallium scans were performed with a gamma camera 48 hours after the intravenous injection of $3 \mathrm{mCi}$ of gallium 67 citrate. The scans were evaluated blindly by one observer, the quantitative National Institutes of Health (NIH) index being used as previously described for pulmonary sarcoidosis. ${ }^{20}$

\section{DATA ANALYSIS}

In the study group of 27 patients only the initial data from each of the 23 untreated patients were considered in examining the correlation between angiotensin converting enzyme activity and $\mathrm{NIH}$ index, and between enzyme activity and bronchoalveolar lavage lymphocyte differential count. In determining the sensitivity and specificity of serum angiotensin converting enzyme activity as a means of detecting high intensity alveolitis, only the data from untreated patients were considered. Correlation between the serum enzyme activity and the NIH index was determined by application of the Spearman Rank test, and between the enzyme activity and bronchoalveolar lavage lymphocyte differential count by the method of least squares regression analysis. The significance of differences between mean angiotensin converting enzyme values was determined by means of a two tailed $t$ test.

\section{Results}

Comparison of serum angiotensin converting enzyme activity with gallium uptake as assessed by the NIH index showed a significant positive correlation between these two variables $(r=0.7, p<$ 0.001 ; fig 1). There was no significant correlation between serum angiotensin converting enzyme activity and bronchoalveolar lavage lymphocytes,

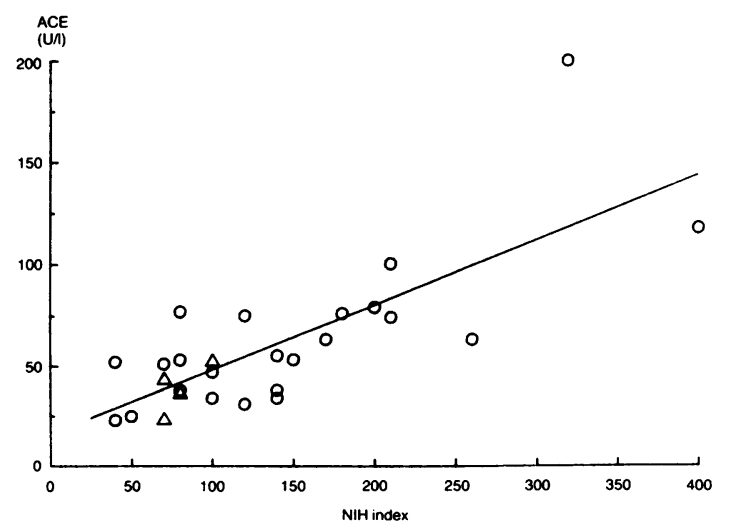

Fig 1 Relationship between serum angiotensin converting enzyme (ACE) activity and the alveolitis of sarcoidosis as measured by the intensity of the gallium 67 scan $(r=0.70$, $p<0.001$ ), in 23 untreated patients with pulmonary sarcoidosis (data on four treated patients indicated by triangles). 
expressed as a percentage of total cells recovered $(\mathrm{r}$ $=0.19, \mathrm{p}=0.36$; fig 2 ). There was a weakly positive correlation between the two components of the alveolitis, the NIH index and bronchoalveolar lavage lymphocyte differential count, which just failed to reach significance $(r=0.30, p=0.06)$.

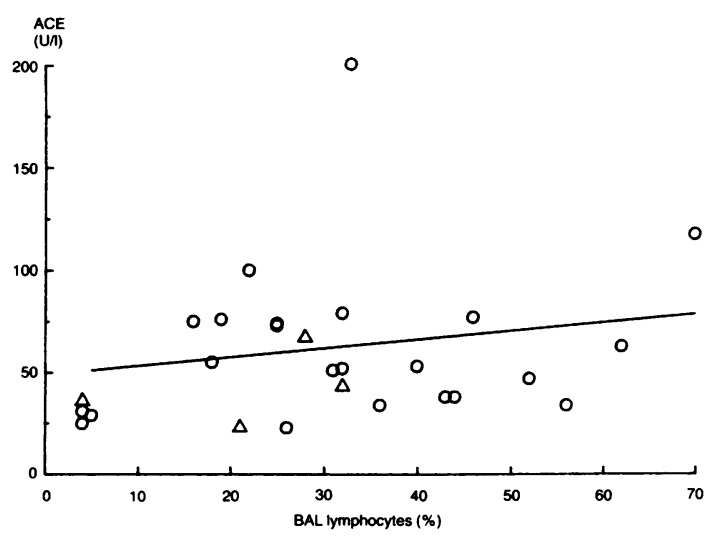

Fig 2 Comparison between serum angiotensin converting enzyme (ACE) activity and the alveolitis of sarcoidosis as measured by the percentage of bronchoalveolar lavage $(B A L)$ cells that are lymphocytes $(r=0.19, p=0.36)$ in 23 untreated patients with pulmonary sarcoidosis (data on four treated patients indicated by triangles).

Patients were designated as having either high intensity alveolitis - if both the bronchoalveolar lavage lymphocyte differential count was greater than $28 \%$ and the NIH gallium index was greater than 50 (12 patients) - or low intensity alveolitis - if either or both of these criteria were not met (11 patients). Serum angiotensin converting enzyme activity failed to discriminate between high and low intensity alveolitis. An increase in activity of the enzyme $(>52 \mathrm{U} / \mathrm{l})$ was found to have a $50 \%$ sensitivity for detecting high intensity alveolitis (of the 12 patients with high intensity alveolitis, six were above this limit), with a specificity of $45 \%$ (of the 11 with no increase, five did have high intensity alveolitis).

There was no significant difference in mean serum angiotensin converting enzyme activity between patients with gallium scans assessed as having an NIH index of 50 or more and those with an index of less than 50. Similarly, there was no significant difference in the mean serum activity of the enzyme between the group of patients with lymphocyte differential counts of $28 \%$ or less and the remainder.

\section{Discussion}

Since the initial observation that serum angiotensin converting enzyme was raised in pulmonary sar- coidosis,' many investigators have attempted to determine the relationship between the serum activity of this enzyme and other indices of disease activity. 467421 Results have differed widely, most authors finding some correlation between angiotensin converting enzyme activity and the results of gallium scans $^{4674}$ and others finding a correlation with bronchoalveolar lavage lymphocytes. ${ }^{21}$ Possible explanations for these discrepancies include the different sources of the enzyme from human tissues. The enzyme has been shown to be produced by normal pulmonary vascular endothelium, ${ }^{22}$ by pulmonary alveolar macrophages, and by the epithelioid cells of pulmonary and extrapulmonary granulomas in sarcoidosis. ${ }^{2.3}$

Our data suggest that angiotensin converting enzyme is related to one component of the alveolitis of sarcoidosis, as we have shown a significant positive correlation between serum activity of the enzyme and the pulmonary uptake of gallium 67 . Current understanding of the mechanism of gallium uptake by the lung suggests that most of the isotope is located in alveolar macrophages. ${ }^{24}$ Intravenously injected gallium is thought to bind to iron binding proteins in the serum, including transferrin, ${ }^{25}$ before sequestration in the tissues. Recent data have shown that alveolar macrophages in sarcoidosis have increased numbers of transferrin receptors on their cell surface. ${ }^{26}$

We have shown no significant correlation between angiotensin converting enzyme and the percentage of lymphocytes recovered in bronchoalveolar lavage fluid. This result is not unexpected, as only one previous study ${ }^{21}$ has shown a correlation between the activity of the enzyme and bronchoalveolar lavage lymphocytes in sarcoidosis, and these cells are not directly responsible for producing the enzyme. We did not find a significant correlation between the percentage lymphocytes recovered at bronchoalveolar lavage and the NIH index. These data suggest that either component of the alveolitis may be active alone. Further studies examining the relationship of the alveolitis to subsequent functional outcome are necessary to confirm the clinical usefulness of estimation of intensity of the alveolitis.

Prediction of disabling fibrosis in sarcoidosis demands a high degree of accuracy because of the small number of patients who subsequently develop disability ${ }^{13}$ and because of the side effects of corticosteroids. Because current methods of staging the alveolitis are invasive or expose the patient to high doses of radiation, ${ }^{20}$ a non-invasive test of disease activity such as determination of angiotensin converting enzyme activity would be useful. Our data do not, however, suggest that this enzyme is reliable as a marker of high intensity alveolitis, being neither 
particularly sensitive nor specific.

We are indebted to Ms LC Allen for her help in this study and to Ms MT Berk for secretarial assistance.

\section{References}

1 Leiberman J. Elevation of serum angiotensinconverting enzyme (ACE) level in sarcoidosis. Am J Med 1975;59:365-72.

2 Fanburg BL, Schoenberger MD, Bachus B, Snider GL. Elevated serum angiotensin 1 converting enzyme in sarcoidosis. Am Rev Respir Dis 1976;114:525-8.

3 DeRemee RA, Rohrbach MS. Serum angiotensinconverting enzyme activity in evaluating the clinical course of sarcoidosis. Ann Intern Med 1980;92:361-5.

4 Schoenberger CI, Line BR, Keogh BA, Hunninghake GW, Crystal RG. Lung inflammation in sarcoidosis: comparison of serum angiotensin-converting enzyme levels with bronchoalveolar lavage and gallium-67 scanning assessment of the T-lymphocyte alveolitis. Thorax 1982;37:19-25.

5 Klech H, Kohn H, Kummer F, Mostbeck A. Assessment of activity in sarcoidosis. Sensitivity and specificity of 67-gallium scintigraphy, serum ACE levels, chest roentgenography, and blood lymphocyte subpopulations. Chest 1982;82:732-8.

6 Leiberman J, Schleissner LA, Nosal A, Sastre A, Mishkin FS. Clinical correlations of serum angiotensin converting enzyme (ACE) in sarcoidosis. A longitudinal study of serum ACE, 67-gallium scans, chest roentgenograms, and pulmonary function. Chest 1983;84:522-8.

7 Gupta RG, Bekerman C, Sicilian L, Oparil S, Pinsky SM, Szidon JP. Gallium-67 citrate scanning and serum angiotensin converting enzyme level in sarcoidosis. Radiology 1982;144:895-9.

8 Beaumont D, Herry JY, Sapene M, Bourguet D, Larzul JJ, De Labarthe B. Gallium-67 in the evaluation of sarcoidosis: correlations with serum angiotensin converting enzyme and bronchoalveolar lavage. Thorax 1982;37: 11-8.

9 Yotsumoto $H$. Longitudinal observations of serum angiotensin-converting enzyme activity in sarcoidisos with and without treatment. Chest 1982;82:556-9.

10 Keogh BA, Hunninghake GW, Line BR, Crystal RG. The alveolitis of pulmonary sarcoidosis: evaluation of natural history and alveolitis-dependent changes in lung function. Am Rev Respir Dis 1983;128:256-65.

11 Mitchell DN, Scadding JG. Sarcoidosis. Am Rev Respir Dis $1974 ; 110: 774-802$.

12 Mayock RL, Bertrand P, Morrison CE, Scott JH. Manifestations of sarcoidosis: analysis of 145 patients with a review of nine series selected from the literature. Am J Med 1963;35:67-89.

13 Sones $\mathbf{M}$, Israel $\mathbf{H}$. Course and prognosis of sarcoidosis. Am J Med 1960;28:84-93.

14 Keogh BA, Crystal RG. Alveolitis: the key to the interstitial lung disorders. Thorax 1982;37:1-10.

15 Haslam PL, Coutts II, Watling AF, et al. Bronchoalveolar lavage features associated with radiographic evidence of fibrosis in pulmonary sarcoidosis. In: Proceedings of the Ninth International Conference on Sarcoidosis. Paris, 1981:209-15.

16 Crystal RG, Bitterman P, Rennard SI, Hance AJ, Keogh BA. Interstitial lung diseases of unknown cause. Disorders characterized by chronic inflammation of the lower respiratory tract. $N$ Engl J Med 1984;310:15466, 235-44.

17 Danel C, Dewar A, Corrin B, Turner-Warwick M, Chretien J. Ultrastructural changes in bronchoalveolar lavage cells in sarcoidosis in comparison with the tissue granuloma. Am J Pathol 1983;112:7-17.

18 Friedland J, Silverstein E. A sensitive Fluorimetric assay for serum angiotensin-converting enzyme. $A m \mathrm{~J}$ Clin Pathol 1976;66:416-24.

19 Braude AC, Chamberlain DW, Rebuck AS. Proportional analysis of respiratory cells obtained by bronchoalveolar lavage. Can Med Assoc J 1982; 126: 1401-3.

20 Line BR, Hunninghake GW, Keogh BA, Jones AE, Johnston GS, Crystal RG. Gallium-67 scanning to stage the alveolitis of sarcoidosis: correlation with clinical studies, pulmonary function studies, and bronchoalveolar lavage. Am Rev Respir Dis 1981;123:440-6.

21 Rossman MD, Dauber JH, Cardillo ME, Daniele RP. Pulmonary sarcoidosis: correlation of serum angiotensin-converting enzyme with blood and bronchoalveolar lymphocytes. Am Rev Respir Dis 1982;125:366-9.

22 Ryan JW, Ryan US, Schultz DR, Whitaker C, Cheung A. Dorer FE. Subcellular localization of pulmonary angiotensin-converting enzyme. Biochem $J$ 1975; 146:497-9.

23 Silverstein E, Pertschuk LP, Friedland J. Immunofluorescent localization of angiotensin converting enzyme in epithelioid and giant cells of sarcoidosis granulomas. Proc Natl Acad Sci USA 1979; 76:6646-8.

24 Braude AC, Chamberlain DW, Rebuck AS. Pulmonary disposition of gallium-67 in humans: concise communication. J Nucl Med 1982;23:574-6.

25 Hoffer P. Gallium: mechanisms. J Nucl Med 1980;21:282-5.

26 Hirata T, Pinkston P, Bitterman P, Hance A, Crystal RG. Alveolar macrophage transferrin receptors in pulmonary sarcoidosis. Am Rev Respir Dis 1984;129(4, part II):A20 (abstract). 